\title{
Changes in diatom and chironomid assemblages of boreal taiga in East Siberia (58N, Lake Aunakit, Russia) during the last $4.2 \mathrm{ka}$
}

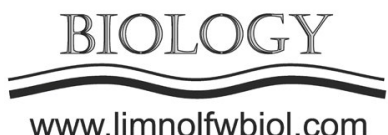

\author{
Vorobyeva S.S. ${ }^{1}$, Enushchenko I.V. ${ }^{1}$, Isaev V.A. ${ }^{2}$, Fedotov A.P. ${ }^{1, *}$ \\ ${ }^{1}$ Limnological Institute of the Siberian Branch of the Russian Academy of Sciences, Ulan-Batorskaya 3, 664033 Irkutsk, Russia \\ ${ }^{2}$ State Nature Reserve 'Vitimsky', Baikalskaya Str., 4a, Bodaybo, 666902, Russia
}

\begin{abstract}
In this study, we analysed a $64 \mathrm{~cm}$ long sediment record from Lake Aunakit located on the Kropotkin Range (East Siberia, Russia) for subfossil diatoms and chironomids to provide an improved reconstruction of the environmental changes in the area for the past $4.2 \mathrm{ka}$. Diatom record is divided into four zones $(0-0.84,0.95-1.25,1.3-2.0$ and 2.0-4.2 $\mathrm{ka} \mathrm{BP})$. Duration of chironomid record is $1.8 \mathrm{ka}$, and this record is divided into five zones 1.8-1.5, 1.5-1.4, 1.4-1.25, 1.25-0.6, and 0.6-0 ka BP.
\end{abstract}

Keywords: diatoms, chironomids, reconstruction, lake, bottom sediments, East Siberia

\section{Introduction}

In the global scale, contrasting climate changes, so-called the Subboreal and Subatlantic periods of the Holocene, characterise time interval during the past $4 \mathrm{ka}$. Modern warming appears clearly in the high latitudes of the Northern Hemisphere. Probably, the previous climate changes were also contrasting, which paleo records from high latitudes indicate.

Diatom and chironomid records are a good proxy of paleoclimate changes. Thus, chironomid records are sensitive to annual summer air temperatures (Brooks and Birks, 2001; Heiri et al., 2003), and a time lag between changes of air temperatures and chironomid taxa is probably minimal. Diatoms are well-known to depend on water temperature, duration of open and close water, insolation and supply of nutrients into the water.
Lake Aunakit is located in the northern part of East Siberia (Russia), on the Kropotkin Ridge (Fig. 1).

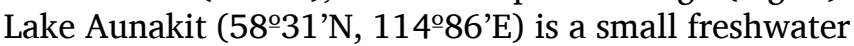
lake located at $1033 \mathrm{~m}$ above sea level, with an area of approximately $0.03 \mathrm{~km}^{2}$. The climate in this region is continental, as reflected by the large differences of temperature. The annual temperatures are from -5 to $-7{ }^{\circ} \mathrm{C}$, whereas the mean January temperatures are lower than $-30{ }^{\circ} \mathrm{C}$ with a drop to $-60{ }^{\circ} \mathrm{C}$, and the mean July ones are $16-18^{\circ} \mathrm{C}$ and up to $38^{\circ} \mathrm{C}$. There is a stable snow cover from October to May. The annual precipitation ranges from 220 to $380 \mathrm{~mm}$, with the precipitation largely (55-60\%) accumulating during the summer months. Duration of the warm period is ca. 130 day/year.

In this study, we attempted to detail environmental changes in the northern part of East Siberia during the middle Holocene by the diatom and chironomid records.

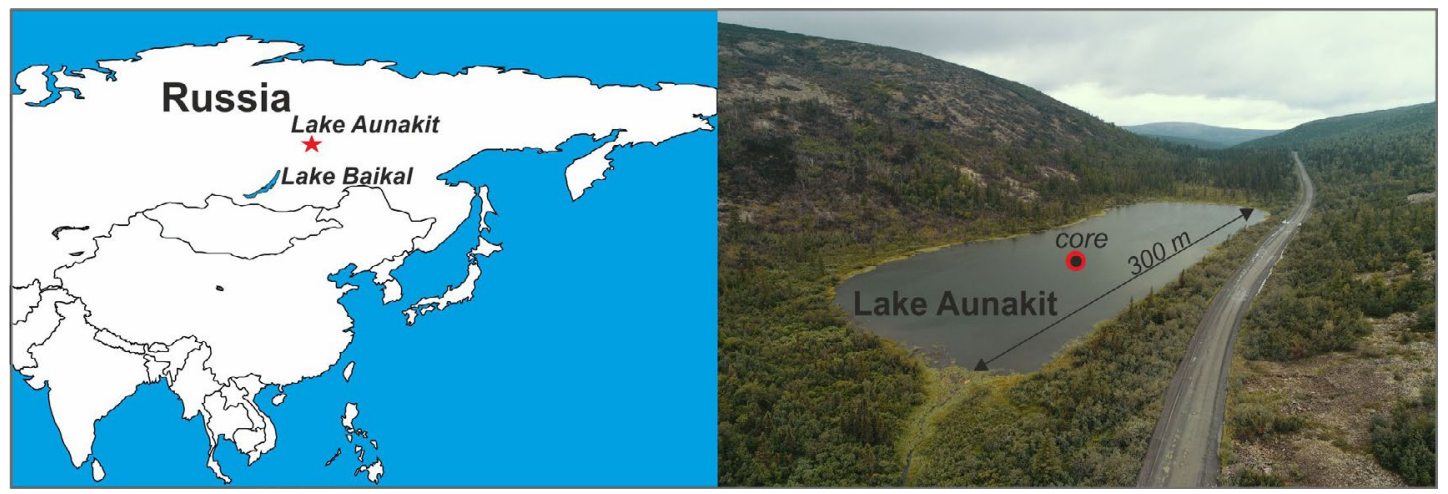

Fig.1. Location of Lake Aunakit

*Corresponding author.

E-mail address: mix@lin.irk.ru (A.P. Fedotov)
(C) Author(s) 2019. This work is distributed under the Creative Commons Attribution 4.0 License. 


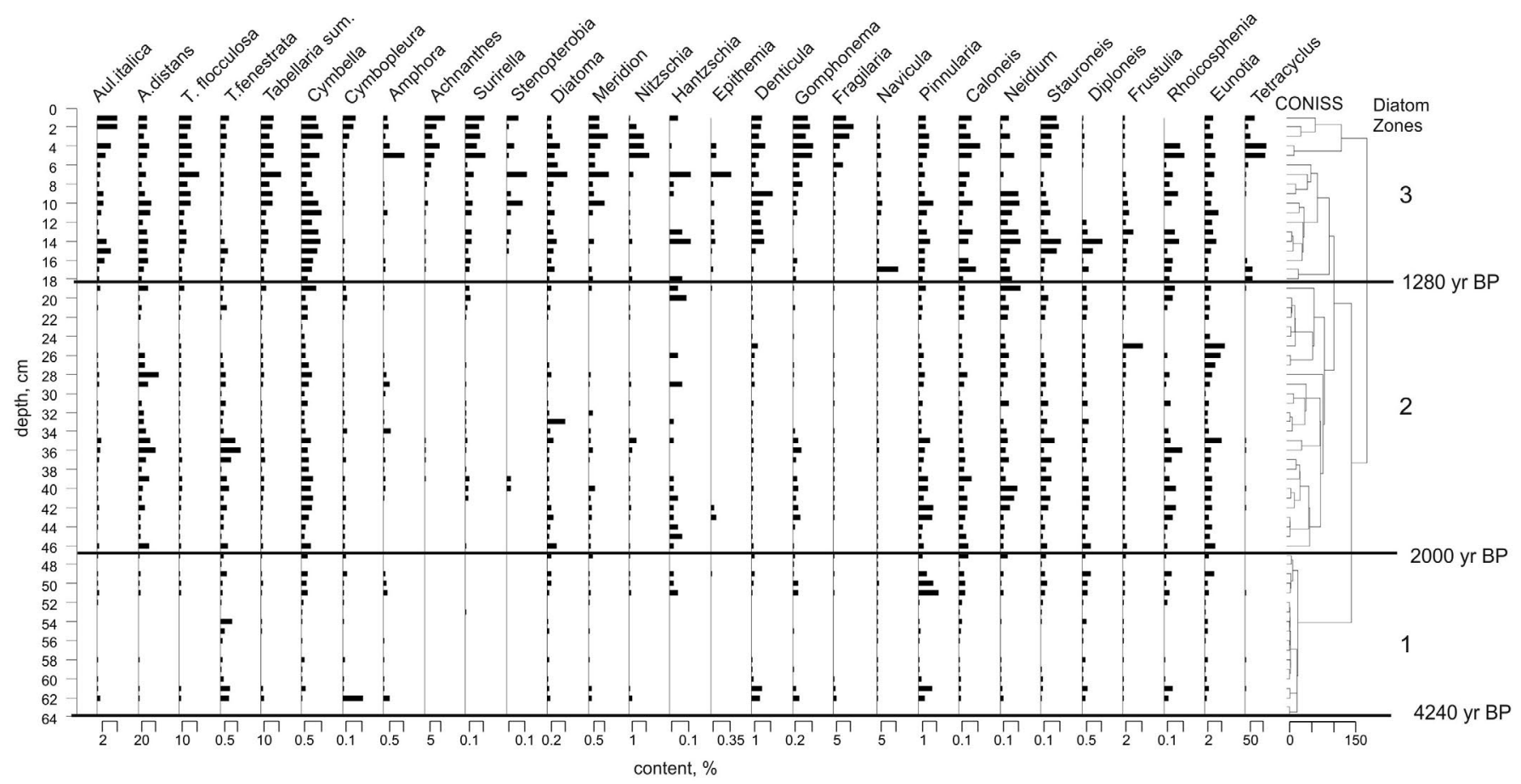

Fig.2. Distribution of main diatom taxa throughout of the sediment core and division of diatom zones (DZ) by CONISS method

\section{Methods}

In 2018, a sediment core was taken from the central part of Lake Aunakit (64 cm long) using a Uwitec Corer sampler. The water depth was $6 \mathrm{~m}$ at the core sampling site.

\subsection{Diatom analyses}

The cores were sampled with $1 \mathrm{~cm}$ intervals. Siliceous microfossils were quantitatively determined by counting permanent smear slides prepared according to the method described in Grachev et al. (1997). Diatom frustules (from 400 to 800 frustules per sample) were identified using keys, atlases and a reference collection (Round et al., 1990; Glezer et al., 1992).

\subsection{Chironomid analyses}

The cores were sampled with $1 \mathrm{~cm}$ intervals. Samples of $1 \mathrm{~cm}^{3}$ for chironomid analysis were immersed in concentrate HF; after $24 \mathrm{~h}$ the acid was washed out, and, then, the samples were washed through a $100-\mu \mathrm{m}$ sieve with a sampling resolution of $1 \mathrm{~cm}$. The remains of chironomid head capsules were identified according to Pankratova (1970; 1977; 1983) and Makarchenko (1982; 2006).

\subsection{Depth-age model}

The total radiocarbon content in the graphitized samples was quantified by AMS engineered at Budker Institute of Nuclear Physics (Novosibirsk, Russia). The total $14 \mathrm{C}$ content was measured relative to ${ }^{13} \mathrm{C}$ and normalized to NIST standards). Chemical pre-treatment and graphitization of samples were carried out in Laboratory of Radiocarbon Methods of Analysis at Novosibirsk State University using laboratory installation (Lysikov et al., 2018). Four sediment layers were dated (Table 1). Calendar date was evaluated from the radiocarbon one by CalPal ver.1.5.

\section{Results and Discussion}

Table 1. Results of AMS radiocarbon dating of the lake bottom sediments

\begin{tabular}{|c|c|c|c|}
\hline $\begin{array}{c}\text { Depth below } \\
\text { sediment surface, cm }\end{array}$ & Lab.code & $\begin{array}{c}{ }^{14} \text { C age, } \\
\text { yrs BP }\end{array}$ & $\begin{array}{c}\text { Calendar age, } \\
\text { yrs cal BP }\end{array}$ \\
\hline 7.5 & BINP_NSU_1394 & $1077 \pm 65$ & $1006 \pm 60$ \\
$25^{*}$ & BINP_NSU_1395 & $2416 \pm 74$ & $2524 \pm 65$ \\
47.5 & BINP_NSU_1396 & $2072 \pm 66$ & $2052 \pm 65$ \\
63.5 & BINP_NSU_1397 & $3783 \pm 66$ & $4172 \pm 65$ \\
\hline
\end{tabular}

* the sample most likely contains old carbon. 


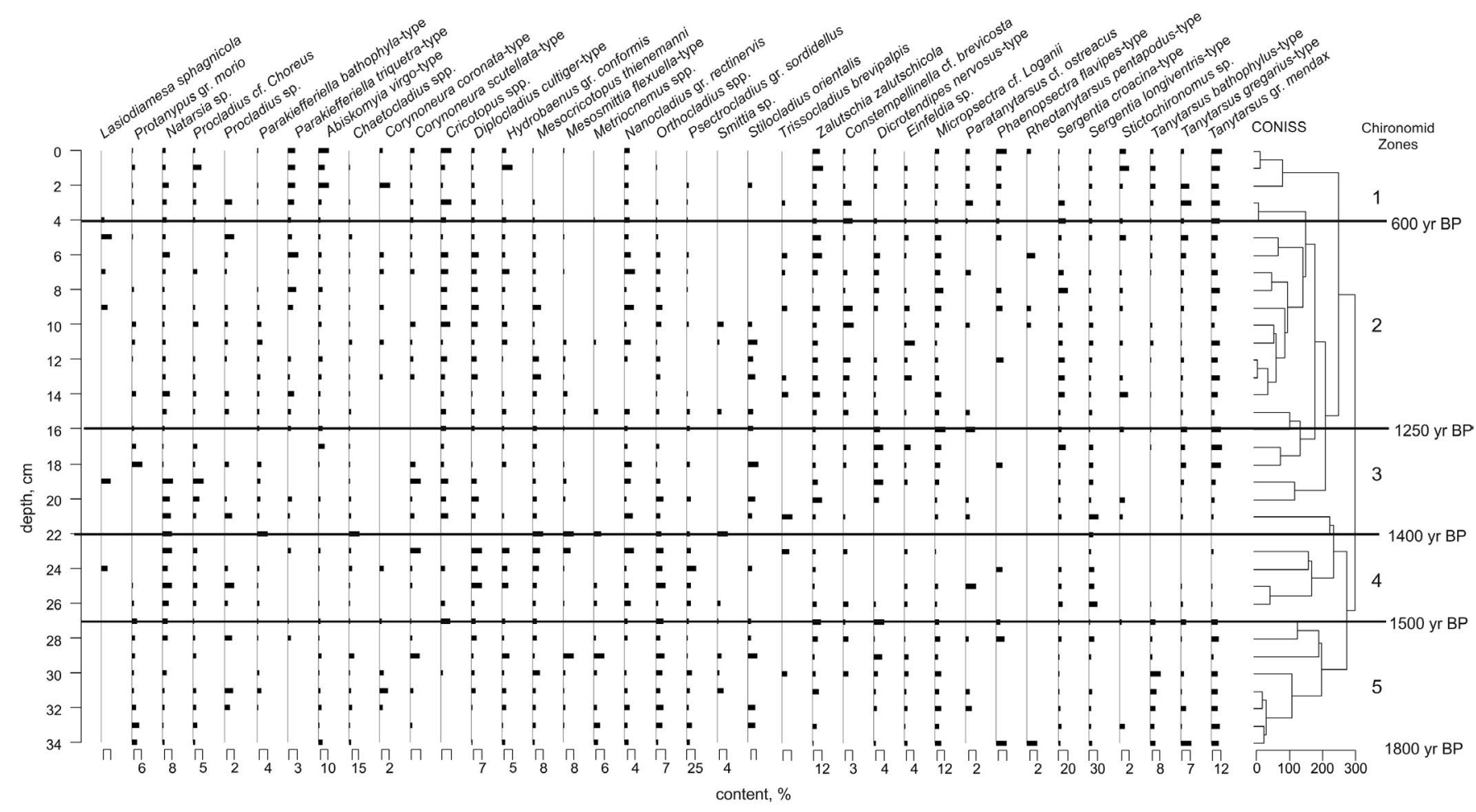

Fig.3. Distribution of main chironomid taxa throughout the sediment core and division of chironomid zones (ChZ) by CONISS method

According to the obtained dates, the bottom layer $(64 \mathrm{~cm}$ ) in sediment core was formed ca. $4.2 \mathrm{ka}$ (Table 1). Only one data $(25 \mathrm{~cm})$ shows nonlinear chronology due to the presence of old carbon.

Ninety-two species represent diatom assemblages of the sediment core. The number of plankton diatoms changed from 0.02 to $126.6 \times 10^{6}$ frustules $\mathrm{g}^{-1}$ dry weight throughout the core. There were six plankton species, with Aulacoseira italica (Ehrenberg) Simonsen (up to $8.14 \times 10^{6}$ frustules $\mathrm{g}^{-1}$ ), A. distans (Ehrenberg) Simonsen (up to $117.2 \times 10^{6}$ frustules $\mathrm{g}^{-1}$ ), Tabellaria flocculosa (Roth) Kützing (67×10 frustules $\left.\mathrm{g}^{-1}\right)$, and $T$. fenestrata (Lyngbye) Kützing $\left(2.4 \times 10^{6}\right.$ frustules $\left.\mathrm{g}^{-1}\right)$ dominating in all records (Fig. 2). Single frustules of two species of the genera Cyclotella were found in the uppermost sediment layer. These dominant species are typical of oligotrophic-mezotrophic freshwater lakes with low or neutral pH (Barinova et al., 2006; Kharitonov and Genkal, 2012).

The number of benthic diatoms was 0.014$287.3 \times 10^{6}$ frustules $\mathrm{g}^{-1}$. There was a great number of Tetracyclus (up to $228.7 \times 10^{6}$ frustules $\mathrm{g}^{-1}$ ), Eunotia (up to $12.7 \times 10^{6}$ frustules $\mathrm{g}^{-1}$ ), Frustulia (up to $12.7 \times 10^{6}$ frustules $\mathrm{g}^{-1}$ ), and Achnanthes (up to $19.5 \times 10^{6}$ frustules $\mathrm{g}^{-1}$ ). Content of chrysophycean cysts was $10-112 \times 10^{6}$ specimens $\mathrm{g}^{-1}$.

Based on CONISS analysis, we divided diatom records into four local zones (DZ) (Fig. 2). In the DZ-1 (0-6 $\mathrm{cm}$ below the sediment surface, bss, ca. 0-0.84 ka BP), the total content of diatoms was $98.24-397 \times 10^{6}$ frustules $\mathrm{g}^{-1}$. Benthic diatoms were dominant, 53.6$73.7 \%$ of total diatoms, with the highest content of Tetracyclus. Aulacoseira distans (14.2-24.0\%) and Tabellaria flocculosa (10.4-18.2\%) dominated plankton diatoms.
The DZ-2 (7-18 cm bss, ca. 0.95-1.25 ka BP) was characterised by a decrease in diatoms to 57.1$159.3 \times 10^{6}$ frustules $\mathrm{g}^{-1}$. A. distans $(16-56.7 \%)$ and $T$. flocculosa (6-43.3\%) dominated diatom assemblages.

In the DZ-3 (19-46 cm bss, ca. 1.3-2.0 ka BP), the number of diatoms varied strongly between 0.41 and $141.84 \times 10^{6}$ frustules $\mathrm{g}^{-1}$. The minimum content of frustules was at $23 \mathrm{~cm}$ bss. A. distans (21.3-82.6\%), $T$. flocculosa (5.2-18.3\%) and Eunotia (2.6-36.6\%) fully dominated diatom assemblage.

In the DZ-4 (47-64 cm bss, ca. 2.0-4.2 ka BP), the total diatom content varied from 0.014 to $37.8 \times 10^{6}$ frustules $\mathrm{g}^{-1}$. A. distans (18.8-46\%), T. flocculosa (5.5$24.1 \%)$ and Eunotia (3.5-21.6\%) prevailed in the zone.

In general, diatom records indicate that environmental condition contrast changed three times. The first period was since $c a$. $2.0 \mathrm{ka} \mathrm{BP}$, when contents of plankton diatoms sharply began to increase. The second period was since $c a$. 1.7-1.3 ka BP, when contents of diatoms and chrysophycean cysts rapidly turned from the highest to the lowest ones. The third period is from $1.25 \mathrm{ka}$ BP to the present time, when species diatom diversity is high.

We studied chironomidae assemblages for the upper $34 \mathrm{~cm}$ of the core. The assemblages showed 55 larval forms of 46 genera and 5 subfamilies (Podonominae, Tanypodinae, Diamesinae, Orthocladiinae, and Chironominae). Based on CONISS analysis, we divided chironomid records into five local zones (ChZ) (Fig. 3). The ChZ-1 (0-4 cm bss, ca. 0-0.6 ka BP) consisted of Abiskomyia virgo-type, Zalutschia zalutschicola, Sergentia longiventris-type and Tanytarsus gr. Mendax. Natarsia sp., Procladius cf. choreus, Parakiefferiella triquetra, Chaetocladius spp., Diplocladius cultiger-type, Hydrobaenus gr. conformis, Nanocladius gr. 
rectinervis, Psectrocladius gr. sordidellus, and Micropsectra loganii-type were minor.

In the ChZ-2 (4-16 cm bss, ca. 0.6-1.25 ka BP) and the ChZ-3 (16-22 cm bss, ca. 1.25-1.4 ka BP) Zalutschia zalutschicola, Sergentia longiventris-type and Tanytarsus gr. Mendax dominated. Procladius cf. choreus, Chaetocladius spp., Diplocladius cultiger-type, Hydrobaenus gr. conformis, Nanocladius gr. rectinervis, and Psectrocladius gr. Sordidellus were minor. In addition, the number of head capsules of Protanypus gr. Morio sharply increased in the ChZ-3. Percentage of Natarsia sp., Parakiefferiella bathophyla-type, Diplocladius cultigertype, Nanocladius gr. rectinervis, Constempellinella cf. brevicosta, Dicrotendipes nervosus-type, Einfeldia sp., Micropsectra loganii-type, Sergentia croacina-type, and Tanytarsus gregarius-type slightly increased in the ChZ-2 and 3 compared to those in the ChZ-1.

Throughout the ChZ-4 (22-27 cm bss, ca. 1.4-1.5 ka BP) Natarsia sp., Diplocladius cultigertype, Mesocricotopus thienemanni, Orthocladius sp., Psectrocladius gr. sordidellus, and Sergentia longiventristype dominated. However, the ratio of Zalutschia zalutschicola and Micropsectra logani reduced. In the sediment layer of $22-23 \mathrm{~cm}$ bss, Diamesa aberrata, Parakiefferiella bathophyla-type, Chaetocladius spp., Metriocnemus spp., Mesosmittia flexuella-type, Smittia sp., and Sergentia longiventris-type dominated.

The ChZ-5 (27-34 cm bss, ca.1.5-1.8 ka BP) is characterised by a sharp increase in Diamesa stenboecki and Tanytarsus bathophylus-type, as well as a great number of Protanypus gr. Morio.

Chironomid compositions of the ChZ-1,2,3 and 5 indicate that regional climate and lake ecological conditions were similar to modern ones. The ChZ-4 shows the low water level in the lake. Thus, Protanypus gr. Morio and Zalutschia zalutschicola inhabiting deep water (Walker et al., 1991; Olander et al., 1997) disappeared from chironomid assemblage. In addition, riverine and stream species also disappeared. It is likely that an inflow into Lake Aunakit strongly reduced. In addition, the number of frustules of plankton diatoms also was minimal within this span.

\section{Conclusions}

The core from Lake Aunakit formed over the past 4.2 ka BP. Ninety-two species represent diatom assemblages; however, only $A$. distans, T. flocculosa, Tetracyclus and Eunotia dominated the records. Four diatom zones divided 0-0.84, 0.95-1.25, 1.3-2.0, and 2.0-4.2 ka BP. The highest diatom diversity was in the past $1.25 \mathrm{ka}$. Chironomid assemblages of the upper 34 $\mathrm{cm}$ of the core showed 55 larval forms of 46 genera and 5 subfamilies (Podonominae, Tanypodinae, Diamesinae, Orthocladiinae, Chironominae). Changes in chironomid taxa occurred between 0-0.6-1.25-1.41.5-1.8 ka BP. The most dramatic changes in diatom and chironomid assemblages occurred 1.3-1.5 ka BP. Most likely, the lake level was low at that time.

\section{Acknowledgements}

This study was supported by basic funding No. 0345-2016-0006 (AAAA-A16-116122110063-0), RFBR-17-29-05016 (financial support of laboratory materials and equipment) and RFBR-16-05-00342 (financial support of fieldwork and AMS dating). We thank T.O. Zheleznyakova for diatom analysis, E.V. Parkhomchuk, P.N. Kalinkin and S.A. Rastigeev for AMS dating.

\section{References}

Barinova S.S., Medvedeva L.A., Anissimova O.V. 2006. Diversity of algal indicators in environmental assessment. Tel-Aviv: Pilies Studio. (in Russian)

Brooks S.J., Birks H.J.B. 2001. Chironomid-inferred air temperatures from Lateglacial and Holocene sites in northwest Europe: progress and problems. Quaternary Science Reviews 20: 1723-1741.

Glezer S.I., Makarova A.I., Moisseeva A.I., Nikolaev V.A. (Eds.). 1992. The diatoms of the USSR (fossil and recent). II (2). S.-Petersburg: Nauka. (in Russian)

Grachev M.A., Likhoshway E.V., Vorobieva S.S. et al. 1997. Signals of the paleoclimates of the Upper Pleistocene in the sediments of Lake Baikal. Russian Geology and Geophysics 35: 994-1018. (in Russian)

Heiri O., Lotter A.F., Hausman S., Kienast F. 2003. A chironomid-based Holocene summer air temperature reconstruction from the Swiss Alps. The Holocene 13: 477-484.

Kharitonov V.G., Genkal S.I. 2012. Diatoms of the Elgygytgyn Lake and its vicinities (Chukotka). Magadan: NESC FEB RAS.

Lysikov A.I., Kalinkin P.N., Sashkina K.A. et al. 2018. Novel simplified absorption-catalytic method of sample preparation for AMS analysis designed at the laboratory of radiocarbon methods of analysis (LRMA) in Novosibirsk Akademgorodok. International Journal of Mass-spectrometry 433: 11-18.

Makarchenko E.A. 1982. Chironomids of the genus Protanypus Kieffer (Diptera, Chironomidae) of USSR Far East. In: Biology of fresh-water insects of Far East. Far East Scientific Centre, Vladivostok, pp. 124-144. (in Russian)

Makarchenko E.A. 2006. Chironomidae - non-biting midges. In: Sidorenko V.S., Kupyanskaya A.N., Leley A.S. (Eds.), The insects of Russian Far East. Vol. VI. Diptera and Siphonoptera. Pt. 4. Key of the insects of Russian Far East. Vladivostok, pp. 204-734. (in Russian)

Olander H., Korhola A., Blom T. 1997. Surface sediment Chironomidae (Insecta: Diptera) distribution along an ecotonal transect in subarctic Fennoscandia: developing a tool for paleotemperature reconstructions. Journal of Paleolimnology 18: 45-59.

Pankratova V.Ya. 1970. Larvae and pupae of non-biting midges of the subfamilies Orthocladiinae (Diptera, Chironomidae $=$ Tendipedidae) of the USSR fauna. Leningrad: Nauka. (in Russian)

Pankratova V.Ya. 1977. Larvae and pupae of non-biting midges of the subfamilies Podonominae and Tanypodinae (Diptera, Chironomidae $=$ Tendipedidae) of the USSR fauna. Leningrad: Nauka. (in Russian)

Pankratova V.Ya. 1983. Larvae and pupae of non-biting midges of the subfamilies Chironominae (Diptera, Chironomidae $=$ Tendipedidae) of the USSR fauna. Leningrad: Nauka. (in Russian)

Round F.E., Crawford R.M., Mann D.G. 1990. The Diatoms. Biology and morphology of the genera. Cambrige: Cambrige University Press. 
Walker I.R., Smol J.P., Engstrom D.R. et al. 1991. An assessment of Chironomidae as quantative indicators of past climatic changes. Canadian Journal of Fisheries and Aquatic Sciences 48: 975-987. 